\title{
Designing future products: what difficulties do designers encounter and how can their creative process be supported?
}

\author{
Nathalie Bonnardel ${ }^{\mathrm{a}, \mathrm{b}^{*}}$ \\ ${ }^{a}$ Center for Research on Psychology of Cognition, Language and Emotion (PsyCLE-E.A. \\ 3273), Aix-Marseille University, 29 avenue Robert Schuman, 13621 Aix-en-Provence Cedex 1, \\ France \\ ${ }^{\mathrm{b}}$ I.U.F. (University Institute of France)
}

\begin{abstract}
To remain competitive, companies must regularly offer new products to consumers. A major challenge for designers is therefore to come up with design solutions and define products that are both new and adapted to future users and usages. Although classic methods and ergonomic recommendations are useful in most run-of-the-mill design contexts, they are of limited benefit when the design situation requires greater creativity. This paper therefore addresses issues related to product design by pursuing a triple objective: (1) highlight the difficulties encountered by designers in imagining and conceiving new products, (2) find out which conditions could help designers come up with creative ideas for innovative products, and (3) suggest methods and tools to support designers' creative process and help them take other stakeholders' needs and expectations into consideration.
\end{abstract}

Keywords: Creativity, design, creative ideas, constraints, design support systems.

* Corresponding author. E-mail: Nathalie.Bonnardel@univ-provence.fr. Tel: +33 (0)4 429537 40. Fax: +33 (0)4 42953720. 


\section{Introduction}

Coming up with design solutions and defining products that are both new and adapted to future users and usages is a vital task for designers $[6,7]$. Indeed, in order to stay competitive, companies must regularly bring out new products for consumers to try.

User-centered design methods can help designers understand users' expectations, needs and limitations, and take them into consideration during the design process. They include the "personas" method $[16,38]$, ergonomic recommendations (e.g., [36]), and Ergonomic Criteria [40]. Such user-centered design methods have undeniable benefits in terms of taking users into account, but when design situations require greater creativity, they may make it harder for designers to imagine and conceive future products.

This raises several questions: What specific difficulties do designers encounter when conceiving future products? How can designers anticipate-or even invent-the needs of future users? How can designers come up with creative designs for future products? How can such complex creative processes be supported? How can future products be assessed when users are not familiar with the use of such innovative products?

This paper addresses some of these issues by pursuing three complementary objectives:

- highlight the difficulty encountered by designers in conceiving future products by adopting a cognitive approach to creative design;

- explore, through the use of complementary methods (interviews, questionnaires, and experiments), how designers come up with creative ideas for innovative products;

- suggest methods and tools for supporting designers' creative process.

\section{Cognitive approach to creative design and designers' difficulties}

\subsection{Cognitive approach}

From a cognitive point of view, one of the main characteristics of the design process is that it can be considered as a problem-solving process, in that no solution can be directly applied to resolve it. Moreover, design problems are regarded as "ill-structured" or "ill-defined" [23, 43, 44], insofar as designers" mental representations are initially incomplete and imprecise. Only by going through the problemsolving process itself can designers complete their mental representations. Thus, the design problemsolving process has been described as the coevolution of problem and solution spaces [22].

Designers continue to hone their mental representations until they arrive at a design solution that meets the most relevant criteria, depending on the design context. In the case of future products, the design solution must be both new and adapted to the characteristics of the situation or context (e.g., future users and usages; $[6,7])$.

This double criterion is in accordance with the ACM (Analogy and Constraint Management) model proposed by Bonnardel $[4,6]$, which highlights the roles of two main cognitive processes: analogy and constraint management. According to this model, these two processes continuously interact during the design process and contribute to other cognitive processes, too, such as solution evaluation and the consideration of other viewpoints. Analogy and constraint management may have contrasting effects, in line with the notion of divergent and convergent thinking:

- analogy-making encourages designers to extend or open up their "search space" to new ideas;

- constraint management allows designers to give focus to their search for ideas. It also helps them to assess ideas or solutions, and thus gradually delimit their search space, until they find a solution that is both new and adapted to the various constraints.

The A-CM model is partially in line with the Geneplore model $[25,50]$. This last model outlines two generic phases of creativity, a generative phase, in which mental representations, or "preinventive structures", are constructed, and an exploratory phase, when these structures are explored in ways that lead to insights and discoveries. These stages in the production of creative outcomes are seen as distinct, yet cyclical [25]. The preinventive structures come in the form of visual patterns, object forms, mental blends, category exemplars, mental models and verbal combinations.

\subsection{Designers' cognitive difficulties}

In line with the standard definition of "creativity" $[5,31,32]$ and the models described above, designers charged with dreaming up future products can be assumed to encounter at least two main difficulties: (1) finding new ideas, and (2) defining the relevant constraints despite having little or no information 
about either the future products' desirable characteristics and future usages, or future users' needs.

\subsubsection{Difficulty finding new ideas}

The difficulty designers have finding new ideas is highlighted with reference first to models of creativity and design, then to experimental results.

Models of creativity and models of design have several similarities (see [7], for an analysis of these similarities). First, creativity models usually describe a "preparation" phase $[48,27,1]$ and design models an "analysis" phase $[2,34]$. The vocabulary may be different, but in both these stages, creators/designers gather information to help them define and redefine the problem at hand, in line with the design problem characteristics described earlier in this paper. Second, these models describe a "generation" or "synthesis" phase, which results in solutions being put forward. Some authors have also identified an "incubation" stage, involving the formation of ideas in the unconscious mind (see [48]), and/or an "illumination" stage, which corresponds to the sudden conscious awareness of an interesting idea [27, 48]. An additional phase, variously labeled "evaluation" [3, 23, 27, 33], "verification" [48] or "validation" [1] may be followed by a phase in which the solution is communicated to other people $[1,44]$.

The first study described in Section 3 was designed precisely to determine whether these descriptions coincide with designers' own perceptions of their creative activities.

When designing future products, designers frequently try to infer future usage and user expectations by carefully analyzing products similar, to such an extent, to the one to conceive. But what is the effect of such practices? Do they favor the emergence of new ideas?

Several experiments have sought to gauge the effect of examples of pre-existing products on participants' creative output. As such, they relate to both the preparation/analysis and generation/synthesis phases.

Experiments have been conducted with either professional designers, design students, or students with no design training whatsoever, such as psychology students (see, for instance, [20, 30, 39, 45]. In general, half the participants are provided with examples of previous products (or objects), while the other half are not given any examples at all. These experiments have demonstrated a robust effect of "conformity to examples", despite variations in the participants' level of expertise and previous training, or the wording of the instructions. This effect has been called "design fixation" [30] and it inhibits creativity in the sense that participants introduce characteristics of the suggested examples into their output, even when they are explicitly told not to do so and even when the examples have features that do not fit the problem at hand. This conformity effect has also been observed in "no example" conditions, with participants" productions conforming to pre-existing categories [49]. It therefore seems particularly difficult for designers to come up with creative ideas that represent a genuine break with existing objects or products. Although various levels or forms of creativity can be used to define what is creative (see [46]), it is always necessary to introduce features into the design solutions that cannot be found in existing products.

The second study presented in Section 3 was designed to pinpoint the conditions that facilitate (or hinder) the generation of new ideas. Section 4 describes computational systems in line with our experimental results.

\subsubsection{Difficulty defining constraints for future products}

A second kind of difficulty encountered by designers who have to conceive future products concerns the definition of relevant constraints for constructing their mental representations of future products and usages. Nevertheless, the management of such constraints is crucial if they are to meet the criterion of "adaptation to the situation or context".

The management of constraints may be undertaken by either conscious or unconscious processes, and several kinds of constraints have been identified (see $[3,4]$ ). Constraints managed by designers may be "internal" - called "constructed" constraints - when they depend on the individual designer's background, previous experience and preferences. Other constraints may be "external", in that they are "prescribed" and set out in a design brief or result from the use of specific materials, tools or systems. Other kinds of constraints, described as "deduced", are inferred by the designers themselves in the course of a "reflective conversation" [42] around "externalizations" of ideas, for instance, in the form of sketches or drafts. This reflection can also result from analyses of the current situation or context, on the basis of analyses of future users' needs or expectations or analyses of the implications of previous choices and decisions. Therefore, constraints arise throughout the 
creative design process, itself constantly linked to other cognitive processes, such as solution generation and evaluation. Together, these different processes help to explain the dynamics of the creative process and are thus in line with the "situated cognition" approach to design $[28,29]$.

Due to their complex management and their key role in the design process $[3,21,19]$, it is particularly challenging for designers to define the constraints that will allow them to anticipate the desirable characteristics of new products adapted to future usages and user needs. First, as pointed out previously, it is difficult for designers to go beyond what they already know. In addition, not all usages can be envisioned by designers, as users typically appropriate products and invent new uses for them. Nevertheless, methods that can help designers anticipate desirable characteristics for future products are evoked in Section 4.

\section{Analyses of factors and processes involved in creative design}

A combination of methods was used in the present research to analyze the factors and processes involved in creative design. First, factors involved in designers' creativity were analyzed on the basis of interviews and questionnaires conducted with professional designers. In addition, an experiment was conducted on one of the main cognitive processes in creative design, namely the evocation of creative ideas.

\subsection{Factors involved in creative design}

To analyze how designers perceive their own creative activities, interviews and questionnaires were administered to 25 professional designers, with 14 mean years of design experience.

\subsubsection{Methods}

The interviews and questionnaires were based on the multivariate approach proposed by Sternberg and Lubart $[47,32]$. The main benefit of this approach is that it encompasses both individual characteristics and environmental conditions. The following factors were taken into account: cognitive factors (e.g., knowledge), conative factors (e.g., related to personality or motivation), emotional factors and environmental factors.

During the interviews, the professional designers were asked about their training and experience, the nature of their creative process and their core work.
Finally, they filled out a questionnaire requiring them to rate all the factors described in the multivariate approach on a 7-point Likert-type scale, to show the importance they attributed to these factors.

\subsubsection{Main results}

The main results allowed us to identify which components of the creative process were perceived by professional designers as being the most important:

- openness to new experiences, new ideas and esthetics (mean score 6.43);

- $\quad$ self- or "reflexive" evaluation (see [3]) (mean score 6.11);

- definition and redefinition of the design problem (mean score 6).

These results are in line with the models of creativity and design described above. In addition, they highlighted the importance of "openness to new experiences, new ideas and esthetics". To determine the best way of nurturing this openness, experimental studies focusing on the process of evocation of new ideas are described below.

\subsection{Evocation of new ideas}

The evocation of new ideas is a process that leads to the generation of ideas. It is also related to design problem definition/redefinition, insofar as it relies on the mental representations that designers construct of the problem at hand (see, for instance, [10]). Several experimental studies have explored this process and sought to identify conditions that might help designers to extend their idea search space $[11,12,8]$. Depending on the experiment, participants are provided with different kinds of examples, such as images vs. words, or images conveying positive vs. negative affects (or emotions). In Bonnardel and Marmèche's study [11], professionals and novice designers were given intra- or interdomain examples. The general hypothesis was that inter-domain analogies would favor the evocation of new ideas, thus contradicting previous studies that had mainly shown a "design fixation" effect.

\subsubsection{Method}

Seventy-five participants took part in the present study: 25 professional designers and 50 "novices" who had no previous training in design.

Participants were asked to design a cybercafé seat in accordance with a design brief. They had to per- 
form this design task while thinking aloud, in order to allow us to identify their sources of inspiration and, on this basis, determine whether they had opened up their search space.

Depending on the experimental conditions, participants were either in a "free" design situation, where they tackled the design problem as they wished (without any examples), or in a "guided" situation, where they were provided with examples. In the latter, participants received either examples of previous objects belonging to the same conceptual domain as the object-to-be-designed, i.e. "intra-domain" examples (as in previous experiments), or examples of objects belonging to other conceptual domains (far removed from that of the object-to-be-designed), i.e. "inter-domain" examples.

\subsubsection{Main results}

Participants' verbalizations were transcribed and three judges analyzed them to identify the number and nature (intra- or inter-domain) of the new sources of inspiration they evoked.

Results showed an effect of the level of design expertise: professional designers evoked significantly more sources of inspiration than novices $(6.4$ vs. 2.9 on average, $F(1,73)=10.33 ; p<.01)$. Furthermore, there was a significant interaction between the nature of the examples and the level of expertise, $F(2,71)=$ 13.33; $p<.001)$. Unlike the novices, the professional designers reacted differently to the examples they were given:

- $\quad$ the intra-domain examples appeared to inhibit the evocation process, in accordance with the "design fixation" effect;

- by contrast, the inter-domain examples appeared to favor the professional designers' evocation process (10.5 sources of inspiration cited in the inter-domain condition on average vs. 3.5 in the intra-domain condition).

Moreover, analysis of these new sources of inspiration showed that the professional designers in the inter-domain condition evoked significantly more inter-domain sources than the participants in the other two conditions (i.e. "free" or "intradomain" conditions) $(F(2,71)=26.71 ; p<.001)$. These results showed that it is possible to help professional designers, though not novices, avoid spontaneously focusing on intra-domain sources of inspiration. Inter-domain examples were found to encourage professional designers to extend their idea search space in order to exploit inter-domain analogies. These results served as a basis for ref- lections on the development of new computational systems support designers (see $\$ 4.2$ ).

\section{Supporting the design of future products}

The analysis of designers' difficulties and the results of the two studies described above were used to suggest methods and computational systems that could be useful in the design of future products.

\subsection{Methods for defining relevant constraints}

A range of ergonomic methods can be used to support designers in defining the relevant constraints for conceiving future products, depending on the evolution of the designers' mental representations and their problem and solution spaces.

First, analyzing the different uses of existing products could help designers understand to such an extent, what might happen with a future product. Thus, situations that share some of the characteristics of the future situation of use can serve as reference situations for reflecting on the use of the future products, their most suitable characteristics and their functionality. However, similarities between existing and future situations can only ever be partial and designers need to think carefully about what should remain similar and what should be innovative. In addition, as previously pointed out, there is a major risk of designers encountering the effect of "design fixation" $[30,39]$ or conformity with existing products or usages, which may limit their ability to come up with creative ideas.

Designers can also use "personas" $[16,38]$, that is, hypothetical characters boasting all the attributes of real people, to figure out future users' profiles and needs. Personas are used in user-centered design to put a "face" on (future) users and avoid a selfcentered approach. Recent studies have tended to show that the use of personas favors designers' ideation process [17].

There are other ways of imagining future users and usages. The Wizard-of-Oz technique can help to elicit users' needs and understand their behavior when using the "future" product (see, for instance, [40]). Other interactive simulations can be based on media such as CAD simulations or virtual reality, which aim to insert users in a potentially realistic environment. Such contexts can place users in situations in which their behavior (in the presence or absence of future products) can be regarded as giving an accurate illustration of future user behavior [18]. Howev- 
er, anticipating use through the analysis of user' behavior is obviously limited, as unexpected uses frequently crop up later [35].

\subsection{Computational systems for coming up with new ideas and respecting constraints}

There are at least two kinds of computational systems that could support designers in finding new ideas and respecting constraints (for more systems, see [14]): systems that encourage designers to extend their idea search space and "critiquing systems" that help them to determine whether the new solutions they have conceived meet the relevant constraints.

\subsubsection{Extending the idea search space}

In line with the experiments described earlier (e.g., [11]), the TRENDS system [15] has been developed to encourage designers to look for new ideas in order to develop creative products. This system features a database of 2 million images drawn from more than 350 Websites. This inspirational material can be accessed via a hybrid semantic search of text and images, formalized in the Conjoint Trends Analysis method. Semantic adjectives used in the design world allow users to submit one-word queries and retrieve related images (see Fig. 1).

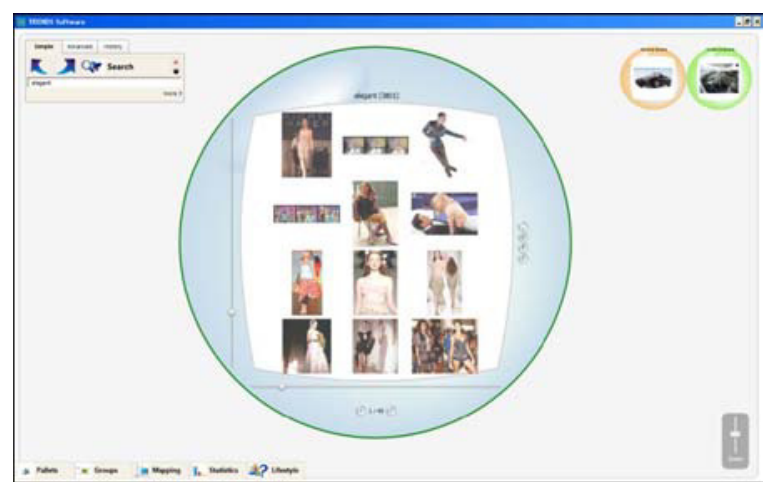

Figure 1: TRENDS software screen capture showing the results of a semantic search with the keyword "elegant".

A recent experimental study analyzed the use of this system by individuals with different levels of design expertise [9].

\subsubsection{Assessing design solutions and respecting constraints}

Critiquing systems allow designers to create design solutions as they wish and then support them in assessing these solutions (see, for instance, [26]).
These systems analyze the design solution in progress, identify its drawbacks (i.e., incompatibility between its characteristics and the constraints it has to respect) and provide the user with critiques consisting of messages pointing out weaknesses in the design solution. To investigate the impact of these systems, a critiquing system was specially designed, built and assessed in relation to the design of Voice Dialog interfaces [13].

Specific design support systems could be developed in order to help designers take into account not only prescribed constraints, but also constraints relating to other stakeholders, such as future users or retailers (see [51]).

These different kinds of support systems could favor the design of future products. In particular, professional designers could be supported by a system such as TRENDS for the first stages of the creative design process and by a critiquing system for the following stages. The evocation stage would thus be dissociated from the evaluation one, as recommended in the "brainstorming" method [37]. A way also needs to be found for assessing the use of new technologies to support creativity in design activities. Indeed, new difficulties may arise from the use of radically new support systems. Designers therefore need to be given sufficient time to familiarize themselves with a new system if they are to benefit fully from all its functionalities.

\section{Conclusion}

The different analyses and studies described in the present article highlight two main kinds of difficulty encountered by designers charged with conceiving future products: finding new ideas and defining the relevant constraints. With regard to these difficulties, a combination of methods and computational systems could be used to help designers imagine and conceive new products.

\section{Acknowledgements}

One of the studies described in this paper has been realized under the project ANR CREAPRO (contract ANR-08-CREA-038) and we wish to acknowledge both colleagues and students who contributed to this project. Thanks also to all participants in the studies presented in this paper. 


\section{References}

[1] T.M. Amabile, Creativity in context, Westview Press, Boulder, Co., 1996.

[2] M. Asimov, M., Introduction to design, Prentice-Hall, Englewood Cliffs, N.J., 1962.

[3] N. Bonnardel, L'évaluation réflexive dans la dynamique de l'activité du concepteur [The reflexive evaluation in the dynamics of the designer's activity], in: Pilotage et évaluation des activités de conception, J. Perrin, ed., L'Harmattan, Paris, 1999 , pp. 87-105.

[4] N. Bonnardel, Towards understanding and supporting creativity in design: Analogies in a constrained cognitive environment, Knowledge-Based Systems, 13 (2000), 505-513.

[5] N. Bonnardel, Créativité, in : Dictionnaire des sciences cognitives [dictionary of cognitive science], G. Tiberghien, ed., Armand Colin - VUEF, Paris, 2002, pp. 95-97.

[6] N. Bonnardel, Créativité et conception: Approches cognitives et ergonomiques [Creativity and design: Cognitive and ergonomics approaches], Solal, Marseille, 2006.

[7] N. Bonnardel. Activités de conception et créativité: De l'analyse des facteurs cognitifs à l'assistance aux activités de conception créatives [Design activities and creativity: From the analysis of cognitive factors to supporting creative design activities]. Le Travail Humain, 72 (2009), 5-22.

[8] N. Bonnardel, Cognition and emotion in creative design, in: Attention, Representation, and Human Performance: Integration of Cognition, Emotion, and Motivation, S. Masmoudi, A. Naceur \& D. Yun Dai, eds., PsyPress, London, in press.

[9] N. Bonnardel and C. Bouchard, Towards supporting creative design: Analysis of the use of the TRENDS system according to designers' expertise, Proceedings of the $8^{\text {th }}$ ACM Conference on Creativity and Cognition, ACM Press, Atlanta, 2011.

[10]N. Bonnardel, A. Didierjean and E. Marmèche, Analogie et résolution de problèmes [Analogy and problem-solving], in: Métaphores et Analogies, C. Tijus, ed., Hermès, Paris, 2003, pp. 115-149.

[11]N. Bonnardel and E. Marmèche, Evocation processes by novice and expert designers: Towards stimulating analogical thinking, Creativity and Innovation Management, 13 (2004), 176-186.

[12] N. Bonnardel and E. Marmèche, Towards supporting evocation processes in creative design: A cognitive approach, International Journal of Human-Computer Studies, 63 (2005), 442435.

[13] N. Bonnardel and T. Sumner, Supporting evaluation in design, Acta Psychologica, 91 (1996), 221-244.

[14] N. Bonnardel and F. Zenasni, The impact of technology on creativity in design: An enhancement? Creativity \& Innovation Management, 19 (2010), 180-191.

[15] C. Bouchard, J.F. Omhover, C. Mougenot, A. Aoussat, and S. Westerman, TRENDS: a content-based information retrieval system for designers, Proceedings of Design Computing and Cognition - DCC08, Atlanta, 2008.

[16] E. Brangier and C. Bornet, Persona: A method to produce representations focused on consumers' needs, in: Human Factors and ergonomics in Consumer Product Design: methods and techniques, W. Karwowski, M. Soares, N. Stanton, eds, 2011, pp. 37-61.

[17] E. Brangier, C. Bornet, J.M.C. Bastien, G. Michel and R. Vivian, Mesure de la capacité des personas à générer des idées dans la conception de projets WEB, Le Travail Humain, sous presse.

[18] J.M. Burkhardt, B. Bardy and D. Lourdeaux, Immersion, réalisme et présence dans la conception et l'évaluation des en- vironnements virtuels [Immersion, realism and presence in the evaluation of virtual environments], Psychologie Française, 48 (2003), 35-52.

[19]A. Chevalier and J. Cégarra, Une approche psychologique de la notion de contrainte en résolution de problèmes, Le Travail Humain, 71 (2008), 173-198.

[20]E.G. Chrysikou and R.W. Weisberg, Following the wrong footsteps: Fixation effects of pictorial examples in a design problem-solving task, Journal of Experimental Psychology: Learning, Memory, and Cognition, 31 (2005), 1134-1148.

[21]F. Darses, Contraintes (gestion de contraintes dans les activités de conception), in: Vocabulaire de l'Ergonomie, M. de Montmollin, ed., Octarès, Toulouse, 1997, pp. 101-106.

[22]K. Dorst and N. Cross, Creativity in the design process: Coevolution of problem-solution,. Design Studies, 22 (2001), 425-437.

[23]C.M. Eastman, Cognitive processes and ill-defined problems: A case study from design, Proceedings of the 1st International Joint Conference on IA, Washington, DC., 1969, pp. 669-690.

[24]R.A. Finke, Creative insight and preinventive forms, in: The nature of insight, R.J. Sternberg and J.E. Davidson, eds., MIT Press, Cambridge, MA, 1996, pp. 255-280.

[25] R.A. Finke, T.B. Ward and S.M. Smith, Creative cognition: Theory, research, and applications, MIT Press, Cambridge, MA, 1992.

[26] G. Fischer, A.C. Lemke, T. Mastaglio, and A.I. Morch, Critics: an emerging approach to knowledge-based human computer interaction. International Journal of Man-Machine Studies, 35 (1991), 695-721.

[27] M. Gelb, M. Thinking for a change: Discovering the power to create, communicate and lead, Crown Books, New York, 1996.

[28] J.S. Gero, Towards a model of designing which includes its situatedness, in: Universal design theory, H. Grabowski, S. Rude \& G. Grein, eds., Shaker Verlag, Aachen, 1998, pp. 4756.

[29] J.S. Gero and U. Kannengiesser, The situated FunctionBehaviour-Structure framework, Design Studies, 25 (2004), 373-391.

[30] D.G. Jansson and S.M. Smith. Design fixation. Design Studies, 12 (1991), 3-11.

[31] T.I. Lubart. Creativity. In : Thinking and problem solving, R.J. Sternberg, ed., Academic Press, New York, 1994, pp. 289-332.

[32] T.I. Lubart, C. Mouchiroud, S. Tordjman and F. Zenasni. Psychologie de la créativité [Psychology of creativity]. Armand Colin, Paris, 2003.

[33] A. Malhotra, J.C. Thomas, J.M. Carroll and L.A. Miller. Cognitive processes in design. International Journal of ManMachine Studies, 12 (1980), 119-140.

[34] T. McNeill, J.S. Gero and J. Warren, Understanding conceptual electronic design using protocol analysis. Research in Engineering Design, 10 (1998), 129-140.

[35] J. Nelson, S. Buisine and A. Aoussat, Assisting designers in the anticipation of future product use, Asian International Journal of Science and Technology - Production and Manufacturing Engineering, 2 (2009), 25-39.

[36] D.A. Norman. The design of everyday things. Basic Books (Perseus), New York, 1993.

[37] A. Osborn, Applied imagination: Principles and procedures of creative thinking, Scribner's, New York, 1963.

[38] J. Pruitt and T. Adlin, The persona lifecycle, Morgan Kaufmann, San Francisco, CA, 2006.

[39] A.T. Purcell and J.S. Gero. Design and other types of fixation. Design Studies, 17 (1996), 363-383. 
[40] M. Roger, N. Bonnardel and L. Le Bigot, Landmarks' use in speech map navigation tasks. Journal of Environmental Psychology, 31 (2011), 192-199.

[41]D.L. Scapin and J.M.C. Bastien. Ergonomic criteria for evaluating the ergonomic quality of interactive systems. Behaviour \& Information Technology, 16 (1997), 220-231.

[42] D.A. Schön, The reflective practitioner: How professionals think in action, Basic Books, New York, 1983.

[43]H.A. Simon. The structure of ill structured problems, Artif. Intell., 4 (1973), 181-201.

[44]H.A. Simon. Problem forming, problem finding and problem solving in design, in: Design \& Systems, A. Collen \& W. Gasparski, eds., 1995, pp. 245-257.

[45] S.M. Smith, T.B. Ward and J.S. Schumacher. Constraining effects of examples in a creative generation task. Memory \& Cognition, 21 (1993), 837-845.

[46] R.J. Sternberg, J.C. Kaufman and J.E. Pretz. The creativity conundrum: a propulsion model of kinds of creative contribution, Psychology Press, New York, 2002.

[47] R.J. Sternberg and T.I. Lubart, Defying the crowd: creativity in a culture of conformity, Free Press, New York, 1995.

[48] G. Wallas, G. The art of thought, Harcourt-Brace, New York, 1926.

[49] T.B. Ward, M.J. Patterson, C.M. Sifonis, R.A. Dodds and K.N. Saunders. The role of graded category structure in imaginative thought. Memory \& Cognition, 30 (2002), 199-216.

[50] T.B. Ward, S.M. Smith and R.A. Finke, Creative cognition, In: Handbook of creativity, R.J. Sternberg, ed., Cambridge University Press, New York, 1999, pp. 189-212.

[51] A. Wojtczuk, and N. Bonnardel, Designing and assessing everyday objects: Impact of externalisation tools and judges backgrounds, Interacting with Computers, 23 (2011), 337-345. 